\title{
Endovascular Treatment of Cavernous Sinus Dural Arteriovenous Fistulas. Institutional Series, Systematic Review and Meta-Analysis
}

\author{
Andrea M. Alexandre ${ }^{1,2}$ - Carmelo Lucio Sturiale ${ }^{3}$ Andrea Bartolo A Andrea Romi $^{2}$ - Alba Scerrati ${ }^{4,7}$. \\ Maria Elena Flacco ${ }^{5}$ Francesco D'Argento ${ }^{1}$ Luca Scarcia ${ }^{2}$. Giuseppe Garignano' • lacopo Valente ${ }^{1}$. \\ Emilio Lozupone $^{6} \cdot$ Alessandro Pedicelli $^{1}$
}

Received: 22 April 2021 / Accepted: 27 September 2021 / Published online: 15 December 2021

(c) The Author(s) 2021

\begin{abstract}
Purpose Endovascular treatment represents the first-line therapy for cavernous sinus dural arteriovenous fistulas (CS-dAVF); however, different approaches and embolic agents as well as occlusion rates, complications and clinical outcomes are reported among the published series. In this study we performed a comprehensive meta-analysis to investigate clinical and radiological outcomes after endovascular treatment of CS-dAVFs.

Methods PubMed, Ovid Medline, Ovid EMBASE, Scopus, and Web of Science were screened for a comprehensive literature review from 1990 to 2020 regarding series of patients treated for CS-dAVF with endovascular approaches. We performed a proportion meta-analysis estimating the pooled rates of each outcome also including data of patients treated in our center.

Results A total of 22 studies reporting 1043 patients and 1066 procedures were included. Chemosis was reported in 559 out of 1043 patients (45.9\%), proptosis in 498 (41.5\%), and ophthalmoplegia in 344 (23.5\%). A transvenous embolization was preferred in 753 cases $(63.2 \%)$ and coils were used in 712 out of 1066 procedures $(57.8 \%)$. Overall, 85\% (95\% confidence interval, CI 69.5-96.1\%) of patients had a complete resolution of symptoms, while complications occurred in $7.75 \%(95 \%$ CI $3.82-12.7 \%)$ with minimal permanent deficits $(0.15 \%)$. The mortality rate was 1 out of 1043 patients $(<0.001)$.

Conclusion A transvenous coiling is the most common endovascular approach for CS-dAVF, achieving a high percentage of radiological and clinical resolution and low complication rates. Transvenous approaches show less complications than transarterial ones, and coils appear safer than liquid embolic agents.
\end{abstract}

Keywords Cavernous sinus dural arteriovenous fistulas $\cdot$ Carotid-cavernous fistula $\cdot$ Carotico-cavernous d-AVF $\cdot$ DAVF Endovascular treatment

Availability of Data and Material Data are available upon reasonable request.

Andrea M. Alexandre

andrea.alexandre@policlinicogemelli.it

1 UOC Radiologia e Neuroradiologia, Dipartimento di diagnostica per immagini, radioterapia oncologica ed ematologia, Fondazione Policlinico Universitario A. Gemelli IRCCS, Largo A. Gemelli 8, 00168 Roma, Italy

2 Istituto di Radiologia, Università Cattolica del Sacro Cuore, Roma, Italy
3 Dipartimento di Neurochirurgia, Fondazione Policlinico Universitario A. Gemelli IRCCS, Rome, Italy

4 Dipartimento di Neurochirurgia, Ospedale Universitario S. Anna, Ferrara, Italy

5 Dipartimento di Scienze Mediche, Università di Ferrara, Ferrara, Italy

6 UOC Neuroradiologia, Ospedale V. Fazzi, Lecce, Italy

7 Dipartimento di Morfologia, Chirurgia e Medicina Sperimentale, Università di Ferrara, Ferrara, Italy 


\section{Introduction}

Dural arteriovenous fistula of the cavernous sinus (CSdAVF) is an abnormal arteriovenous communication involving the dura mater of the CS wall. These fistulas represent about $16 \%$ of all cerebral dAVFs [1].

Endovascular treatment represents the first-line therapy in the literature $[2,3]$; however, different approaches and embolic agents as well as occlusion rates, complications and clinical outcomes are reported among the published series. [4-6].

This study aims to systematically review all pertinent literature investigating clinical presentation, endovascular approach, embolizing agents, clinico-radiological outcomes and complications of endovascular treatments of CS-dAVFs.

\section{Material and Methods}

\section{Study Design}

This is a systematic review of the literature conducted according to the Preferred Reporting Items for Systematic Review and Meta-Analyses (PRISMA) statement. The review question was formulated according to the PICO criteria, as follows: (P, patients) in the management of CS-dAVF, (I, intervention) what is the endovascular treatment, $(\mathrm{C}$, comparison) that reported the best results, $(\mathrm{O}$, outcomes) in terms of clinical-radiologic outcomes.

This work is part of a non-profit study protocol approved from our hospital's institutional ethics committee: protocol number 2477/21, ID 3585. Informed consent has been obtained from patients who participated in clinical investigations in our institutional series.

\section{Study Selection}

PubMed, Ovid MEDLINE, Ovid EMBASE, Scopus, and the Web of Science were selected as online medical databases to conduct the present systematic review. The following search terms: "dural arteriovenous fistula", "fistula", "indirect", "cavernous sinus" "carotid-cavernous" "carotid cavernous", "carotico-cavernous", "transarterial", "transvenous", "endovascular" were combined using the Boolean operators.

Studies reporting data on patients treated with endovascular techniques for CS-dAVFs were searched. We included all English articles reporting clinical and radiologic data for single patients published between 1990 and 2020. Clinical series reporting less than 10 patients, guidelines, reviews, commentaries, and letters to the editor were excluded.
The first-round search was conducted by 2 reviewers (A.R. and A.B.) who independently screened titles and abstracts for eligibility. The selected full texts and their reference lists (forward search) were screened and evaluated for inclusion in the second round.

In the third round, articles were screened for demographics, dAVF location, clinical onset, dAVF angioarchitectural grading, treatment modalities, occlusion rates, procedural failure, procedure-related complications, radiological clinical outcome at final follow-up.

The article was then excluded in the case of data unavailability, incomplete data, improper data reporting, or unavailability of single patient data (exclusion with a reason). In the fourth round, data were retrieved and added to a database for pooling and statistical analysis (inclusion). Any discordance was solved by consensus with the senior authors (A.M.A. and C.L.S.). In the case of missing data, authors of the respective studies were contacted by email.

Last search was launched in December 2020.

\section{Institutional Series}

We included a retrospective series of patients treated in our center in the period 2009-2020 for CS-dAVFs. All neuroradiological data were retrieved from the institutional PACS, while clinical data were collected through the analysis of all digital records.

\section{Outcomes Measurement}

For every collected patient we recorded: CS-dAVF location, angioarchitectural grading according to Barrow and Cognard classification $[44,45]$, treatment modalities (including approach and embolizing agent), postoperative radiological outcome (scored as: complete resolution, near complete resolution, partial resolution and failed) and clinical outcome at final follow-up (scored as: clinical resolution, partial benefit, persistent and worsened).

Immediate angiographic result at the end of the procedure was classified as: a) complete treatment-in the case of a complete occlusion of the fistula with no evidence of persistent arteriovenous shunt; b) near complete resolution-in the case of minimal residual arteriovenous shunt at final angiographic control (residual flow $<10 \%$ ); c) partial resolution -in the case of persistence of a significant shunting flow; d) failure-when the residual flow appeared substantially unmodified compared with the preoperative status.

\section{Statistical Analysis}

We performed meta-analyses of proportions to estimate the pooled rates of each outcome. Pooled estimates were not 
Fig. 1 Search strategy flowchart

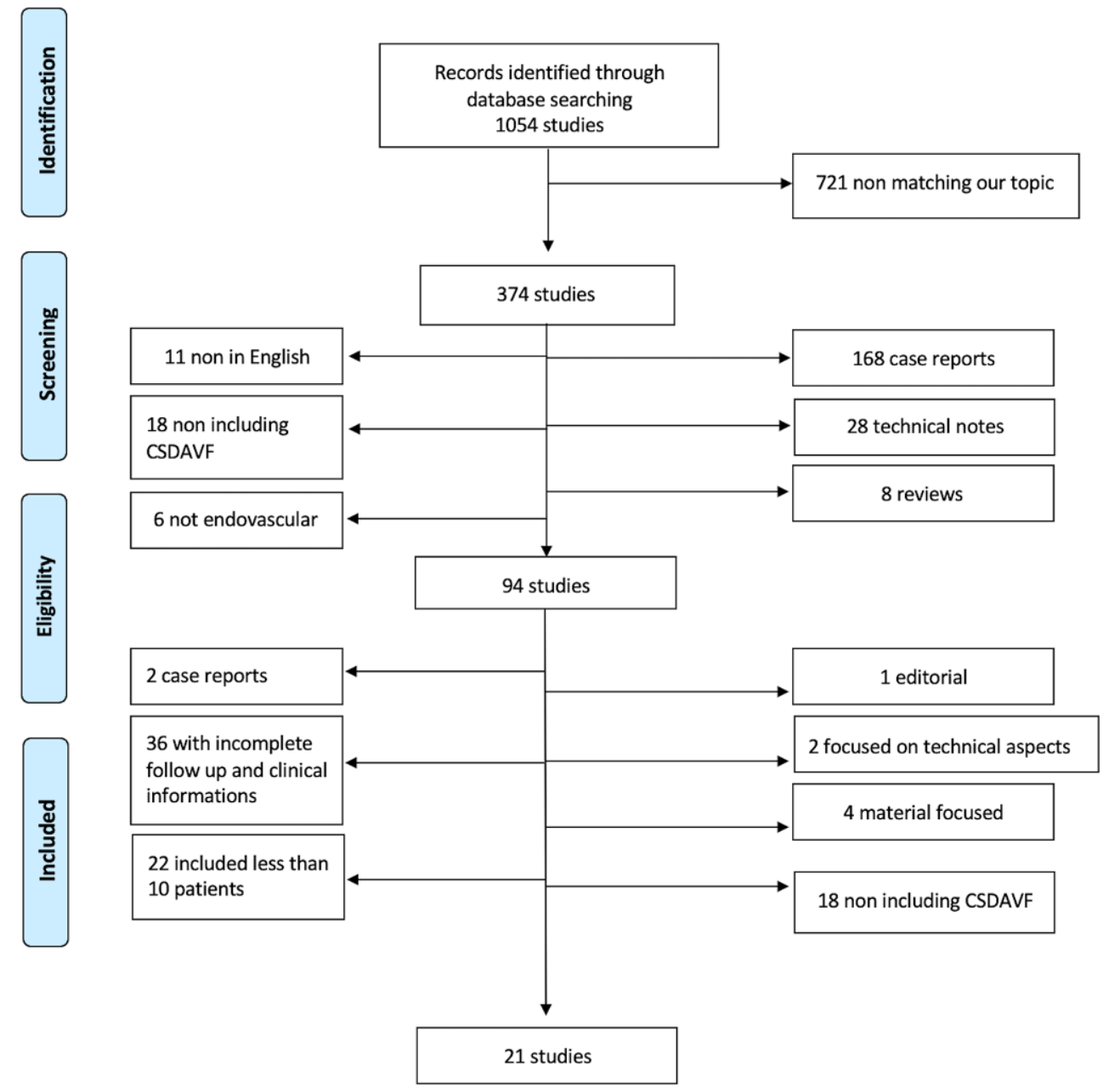

computed when the frequency of an outcome was reported in $<1 \%$ of the sample (only raw proportions and $95 \%$ confidence interval, CI, were reported in such cases). All the included studies were single-group analyses, and no outcome comparison between groups was available, thus no head-to-head meta-analyses were performed. We adopted a random-effect model to account for the interstudy heterogeneity by using Stata software, version 13.1 (Stata Corp., College Station, TX, USA).

\section{Results}

\section{Study Selection and Characteristics}

According to our search strategy, 1054 articles in English language were retrieved through the electronic literature search.

After abstract reading, 721 papers were primarily excluded, while 374 were assessed for eligibility and analyzed in detail as they met our inclusion criteria.
After full-text reading and forward search from the selected papers bibliography, 85 articles were excluded because 22 included less than 10 patients, 36 reported incomplete follow-up or clinical details, 18 did not include CS-dAVFs, 2 were case reports, 1 was an editorial, 2 were focused on technical aspects, and 4 focused on materials.

Subsequently 21 articles [5, 7-26] (19 retrospective, 1 prospective, and 1 mixed papers) reporting patients who underwent endovascular treatment for CS-dAVFs were finally included in this review (Fig. 1).

Finally, we included data from our unpublished series (Alexandre AM, 2021) in the statistical analysis. Details regarding included studies are reported in Table 1, whereas pooled proportions of the analyzed outcomes are reported in Tables 2 and 3. Finally, demographic, clinical and angioarchitectural data regarding our institutional series are reported in Table 4 . In particular, we treated 17 patients ( 8 males, 9 female), with a mean age of $66 \pm 11.7$ years undergoing 21 procedures. Two patients, instead, showed a spontaneous symptoms resolution 1 week after steroids and anticoagulants therapy. All the other patients except one had a complete clinical resolution after treatment. As 
Table 1 Characteristics of the included studies

\begin{tabular}{|c|c|c|c|c|c|c|c|c|}
\hline First author & $\begin{array}{l}\text { Publication } \\
\text { year }\end{array}$ & Country & Study design & $\begin{array}{l}\text { Total sam- } \\
\text { ple }\end{array}$ & $\begin{array}{l}\% \\
\text { Males }\end{array}$ & $\begin{array}{l}\text { Mean age, years } \\
\text { (SD) }\end{array}$ & N. fistulas & $\begin{array}{l}\text { N. proce- } \\
\text { dures }\end{array}$ \\
\hline Klisch & 2003 & Germany & Retrospective & 11 & 18.2 & $62.5(15.5)$ & 14 & 11 \\
\hline Luo & 2009 & China & Retrospective & 11 & 72.7 & $31.0(\mathrm{NR})$ & 11 & 11 \\
\hline $\mathrm{Lv}$ & 2008 & China & Retrospective & 17 & 47.1 & 47.6 (NR) & 20 & 22 \\
\hline Miller & 1995 & USA & Retrospective & 10 & 40.0 & $51.9(14.8)$ & 11 & 10 \\
\hline Nishimuta & 2017 & Japan & Retrospective & 50 & 16.0 & $66.2(11.3)$ & 59 & 50 \\
\hline Pashapour & 2014 & Iran & Prospective & 46 & 63.0 & 36.8 (NR) & 47 & 46 \\
\hline Satow & 2013 & Japan & Retrospective & 20 & 25.0 & $67.5(\mathrm{NR})$ & 21 & 22 \\
\hline Yoshida & 2009 & Japan & Retrospective & 44 & 29.5 & $66.0(\mathrm{NR})$ & 51 & 49 \\
\hline Zhang & 2010 & China & Retrospective & 22 & 72.7 & 49.0 (NR) & 22 & 27 \\
\hline Lee & 2019 & Korea & Retrospective & 121 & 33.1 & $58.0(11.9)$ & 134 & 153 \\
\hline Rhim & 2015 & Korea & Retrospective & 49 & 30.6 & $57.2(\mathrm{NR})$ & 49 & 49 \\
\hline $\mathrm{Yu}$ & 2007 & China & Retrospective & 98 & 25.5 & $57.66(17.2)$ & 98 & 74 \\
\hline Alexander & 2019 & USA & $\begin{array}{l}\text { Retro- and } \\
\text { prospective }\end{array}$ & 267 & 21.7 & $60.9(\mathrm{NR})$ & 267 & 267 \\
\hline Ertl & 2020 & Germany & Retrospective & 33 & 30.3 & $65.5(13.7)$ & 33 & 33 \\
\hline Cha & 2012 & Korea & Retrospective & 14 & 28.6 & $60.6(9.4)$ & 14 & 11 \\
\hline Cheng & 2003 & China & Retrospective & 27 & 11.1 & $60.3(12.9)$ & 27 & 29 \\
\hline $\begin{array}{l}\text { De castro- } \\
\text { Afonso }\end{array}$ & 2017 & Brazil & Retrospective & 62 & 38.7 & $62.7(12.5)$ & 62 & 63 \\
\hline Jiang & 2008 & China & Retrospective & 12 & 25.0 & $54.5(14.9)$ & 12 & 12 \\
\hline Jia & 2018 & Korea & Retrospective & 52 & 23.1 & $59.1(10.7)$ & 52 & 53 \\
\hline Holland & 2018 & Australia & Retrospective & 23 & 21.7 & $64.0(\mathrm{NR})$ & 23 & 13 \\
\hline Griauzde & 2016 & USA & Retrospective & 37 & 29.7 & 64.0 (NR) & 37 & 32 \\
\hline Alexandre & 2021 & Italy & Retrospective & 17 & 47.1 & $66.0(11.7)$ & 17 & 21 \\
\hline
\end{tabular}

$N R$ Not reported

regards to treatment complications, 2 showed transient cranial nerve deficits spontaneously resolved after 3 months, and 1 had a minor ischemic embolic lesion.

\section{Demographic Characteristics}

Overall, we collected 1043 patients suffering from 1081 CS-dAVFs, who underwent a total of 1066 endovascular procedures. Among them, 311 were males (29.8\%) and 732 females $(70.2 \%)$. Mean age was 57.6 years (standard deviation was reported in a minority of series).

\section{dAVFs Characteristics}

According to Barrow classification, 110 patients had a type B fistula (5.7\%), 85 a type C (7.8\%) and 434 a type $\mathrm{D}(31.9 \%)$, while in 414 patients the fistula type was not reported. Considering Cognard classification, 45 patients $(1.9 \%)$ had a type I fistula, 204 a type IIa (17.7\%), 43 a type IIb $(0.8 \%), 75$ a type IIa + b (4.8\%), 10 a type III $(0.07 \%), 14$ a type IV $(0.07 \%), 1$ a type V, while in 651 cases it was not reported. The fistula was located on the right side in 282 patients $(21.3 \%)$, on the left in 262
$(23.3 \%)$, bilaterally in $91(7.4 \%)$, while the side was not reported in 408 (Table 2).

\section{Clinical Presentation}

Chemosis was the most frequent clinical presentation, reported in 559 out of 1043 patients (45.9\%), followed by proptosis in 498 (41.5\%), ophthalmoplegia in $344(23.5 \%)$, pulsatile tinnitus in $166(10.6 \%)$, pain and/or headache in $208(11.1 \%)$, visual acuity reduction in $216(12.4 \%)$, unspecified ocular symptoms in 153 (4.96\%), cranial nerve palsy in $500(31.2 \%)$, an elevated intraocular pressure or glaucoma in 146 (1.92\%), a focal neurological deficit was the less common presentation, reported in 2 patients $(<0.01 \%$-Table 2$)$.

\section{Type of Endovascular Procedure}

The type of embolization approach was reported in 1037 out of 1066 procedures (97.2\%) summarized in Table 2.

A transvenous embolization was used in 753 procedures (63.2\%), a transarterial embolization in $220(14.3 \%)$, a combined approach in $63(4.78 \%)$, while a direct puncture in 1 case $(<0.01 \%)$. In 36 cases out of 1043, a conservative 
Table 2 Pooled proportions of clinical symptoms, classification schemes and treatment strategies in patients with dural arteriovenous fistulas. Data from single studies have been combined using proportion meta-analysis (random-effect model)

\begin{tabular}{|c|c|c|c|c|}
\hline Outcomes (22 studies included) & Patients $(n / N)$ & Raw proportions $(95 \% \mathrm{CI})$ & Pooled proportions $(95 \% \mathrm{CI})$ & $\mathrm{I}^{2}(\%)$ \\
\hline \multicolumn{5}{|l|}{ 1. Barrow classification: } \\
\hline Type A & $0 / 1043$ & - & - & - \\
\hline Type B & $110 / 1043$ & $10.5(8.74-12.6)$ & $5.70(1.51-11.7)$ & 89 \\
\hline Type C & $85 / 1043$ & $8.15(6.56-10.0)$ & $7.79(2.63-14.8)$ & 90 \\
\hline Type D & $434 / 1043$ & $41.6(38.6-44.7)$ & $31.9(12.5-55.0)$ & 98 \\
\hline \multicolumn{5}{|l|}{ 2. Cognard classification: } \\
\hline Type I & $45 / 1043$ & $4.31(3.16-5.73)$ & $1.89(0.0-5.72)$ & 85 \\
\hline Type IIa & $204 / 1043$ & $19.6(17.2-22.1)$ & $17.7(5.60-33.9)$ & 97 \\
\hline Type IIb & $43 / 1043$ & $4.12(2.99-5.51)$ & $0.85(0.0-4.02)$ & 85 \\
\hline Type IIa + b & $75 / 1043$ & $7.19(5.69-8.63)$ & $4.85(0.82-11.0)$ & 90 \\
\hline Type III & $10 / 1043$ & $0.96(0.46-1.77)$ & $0.07(0.0-0.85)$ & 34 \\
\hline Type IV & $14 / 1043$ & $1.34(0.74-2.24)$ & $0.07(0.0-1.10)$ & 55 \\
\hline Type V & $1 / 1043$ & $0.09(0.0-0.5)$ & - & - \\
\hline \multicolumn{5}{|l|}{ 3. Fistula location: } \\
\hline Left & $262 / 1043$ & $25.1(22.5-27.9)$ & $21.3(10.0-35.2)$ & 95 \\
\hline Right & $282 / 1043$ & $27.0(24.4-29.8)$ & $23.3(11.2-37.9)$ & 96 \\
\hline Bilateral & $91 / 1043$ & $8.72(7.08-10.6)$ & $7.41(2.45-14.2)$ & 90 \\
\hline 4. Cortical reflux & $383 / 1043$ & $36.7(33.8-39.7)$ & $26.5(17.3-36.7)$ & 91 \\
\hline \multicolumn{5}{|l|}{ 5. Clinical presentation: } \\
\hline Proptosis & $498 / 1043$ & $47.8(44.7-50.8)$ & $41.5(20.9-63.5)$ & 98 \\
\hline Ophtalmoplegia & $344 / 1043$ & $33.0(30.1-35.9)$ & $23.5(7.80-43.8)$ & 98 \\
\hline Pulsatile tinnitus & $166 / 1043$ & $15.9(13.7-18.3)$ & $10.6(4.54-18.5)$ & 90 \\
\hline Pain and/or headache & $208 / 1043$ & $19.9(17.6-22.5)$ & $11.1(2.73-23.0)$ & 96 \\
\hline Chemosis & $559 / 1043$ & $53.6(50.5-56.7)$ & $45.9(22.0-70.7)$ & 98 \\
\hline Visual acuity reduction & $216 / 1043$ & $20.7(18.3-23.3)$ & $12.4(4.48-23.0)$ & 94 \\
\hline Ocular symptoms & $153 / 1043$ & $14.7(12.6-17.0)$ & $4.96(0.0-16.8)$ & 97 \\
\hline Cranial nerve palsy & $500 / 1043$ & $47.9(44.9-51.0)$ & $31.2(16.8-47.6)$ & 96 \\
\hline Elevated IOP or glaucoma & $146 / 1043$ & $14.0(11.9-16.3)$ & $1.92(0.0-9.03)$ & 94 \\
\hline Focal neurological deficit & $2 / 1043$ & $0.19(0.02-0.69)$ & - & - \\
\hline \multicolumn{5}{|l|}{ 6. Embolization approach ${ }^{\mathrm{a}}$ : } \\
\hline Transarterial & $220 / 1066$ & $20.6(18.2-23.2)$ & $14.3(7.75-22.3)$ & 89 \\
\hline Transvenous & $743 / 1066$ & $69.7(66.8-72.4)$ & $63.2(50.6-65.0)$ & 93 \\
\hline Combined & $63 / 1066$ & $5.91(4.57-7.50)$ & $4.78(1.80-8.72)$ & 78 \\
\hline Direct puncture & $1 / 1066$ & $0.09(0.0-0.5)$ & - & - \\
\hline \multicolumn{5}{|l|}{ 7. Embolizing agent ${ }^{\mathrm{a}}$ : } \\
\hline Coils & $712 / 1066$ & $66.8(63.9-69.6)$ & $57.8(45.4-69.7)$ & 93 \\
\hline Glue & $54 / 1066$ & $5.07(3.83-6.56)$ & $2.78(0.15-7.73)$ & 87 \\
\hline $\mathrm{EVOH}$ & $47 / 1066$ & $4.41(3.26-5.82)$ & $2.97(0.30-7.31)$ & 86 \\
\hline Balloon & $10 / 1066$ & $0.94(0.45-1.72)$ & - & - \\
\hline PVA & $28 / 1066$ & $2.63(1.75-3.77)$ & $0.71(0.0-2.31)$ & 55 \\
\hline Liquid agents & $55 / 1066$ & $5.16(3.91-6.63)$ & $0.25(0.0-2.47)$ & 82 \\
\hline Coils + glue & $33 / 1066$ & $3.10(2.14-4.32)$ & $1.43(0.0-4.32)$ & 79 \\
\hline Coils + EVOH & $32 / 1066$ & $3.0(2.06-4.21)$ & $1.38(0.0-4.54)$ & 82 \\
\hline Others $^{\mathrm{b}}$ & $25 / 1066$ & $2.35(1.52-3.44)$ & $0.19(0.0-1.22)$ & 43 \\
\hline
\end{tabular}

$n$ number of subjects with the outcome, $N$ total number of subjects, $C I$ confidence interval, IOP intraocular pressure, $E V O H$ ethylene vinyl alcohol, $P V A$ Polyvinyl alcohol

${ }^{a}$ The unit of analysis is the number of procedures (instead of number of patients)

bIncluding: stent; EVOH + balloon; stent + balloon; coils + balloon; glue + pva; coils + pva, balloon + stent + coils 
Table 3 Pooled proportions of selected clinical and radiological outcomes in patients with dural arteriovenous fistulas. Data from single studies have been combined using proportion meta-analysis (random-effect model)

\begin{tabular}{|c|c|c|c|c|}
\hline Outcomes (22 studies included) & Patients $(n / N)$ & Raw proportions $(95 \% \mathrm{CI})$ & Pooled proportions $(95 \% \mathrm{CI})$ & $\mathrm{I}^{2}(\%)$ \\
\hline \multicolumn{5}{|c|}{ 1. Postsurgical radiological outcome: } \\
\hline Complete occlusion & $599 / 1043$ & $57.4(54.4-60.5)$ & $79.5(63.0-92.3)$ & 97 \\
\hline Near complete occlusion & $176 / 1043$ & $16.9(14.6-19.3)$ & $6.09(1.16-13.5)$ & 92 \\
\hline Partial occlusion & $38 / 1043$ & $3.64(2.59-4.97)$ & $2.02(0.24-3.88)$ & 74 \\
\hline Failed procedure & $4 / 1043$ & $0.38(0.10-0.98)$ & - & - \\
\hline \multicolumn{5}{|l|}{ 2. Clinical status at final follow-up: } \\
\hline Resolution & $769 / 1043$ & $73.7(70.9-76.4)$ & $85.0(69.5-96.1)$ & 97 \\
\hline Partial benefit & $65 / 1043$ & $6.23(4.84-7.87)$ & $2.45(0.27-5.96)$ & 81 \\
\hline Persistent & $14 / 1043$ & $1.34(0.74-2.24)$ & $0.19(0.0-1.02)$ & 23 \\
\hline Worsened & $16 / 1043$ & $1.53(0.88-2.48)$ & $0.22(0.0-0.95)$ & 9 \\
\hline 3. Complications onset & $95 / 1043$ & $9.11(7.43-11.0)$ & $7.75(3.82-12.7)$ & 80 \\
\hline
\end{tabular}

$n$ number of subjects with the outcome, $N$ total number of subjects, $C I$ confidence interval

treatment allowed the symptoms resolution in 16 patients $(1.5 \%)$.

Considering embolizing agents, coils were used in 712 out of 1066 procedures $(57.8 \%)$, glue in 54 (2.78\%), ethylene vinyl alcohol $(\mathrm{EVOH})$ in $47(2.97 \%)$, balloon in 10 $(<0.01 \%)$, polyvinyl alcohol particles (PVA) in $28(0.7 \%)$, liquid agents in $55(0.25 \%)$, coils plus glue in $33(1.43 \%)$, coils plus $\mathrm{EVOH}$ in 32 (1.38\%), while other alternatives including EVOH plus balloon, stent plus balloon, coils plus balloon, glue plus PVA, coils plus PVA, balloon plus stent and coils were overall used in 25 cases $(0.19 \%)$.

\section{Radiological Outcome}

Immediate radiological outcome was reported in 817 out of $1043(78.3 \%)$ patients. A complete resolution of the fistula was obtained in $79.5 \%(95 \%$ CI, 63.0-92.3\%), a nearcomplete $6.09 \%$ (95\% CI, 1.6-13.5\%), a partial obliteration in $2.02 \%(95 \% \mathrm{CI}, 0.24-3.88 \%)$, while a failure was experienced in 4 patients $(<0.01 \%$, Table 3$)$.

\section{Clinical Outcome and Complications}

Details are reported in Table 3: clinical outcome at final follow-up was reported in 864 out of 1043 (82.8\%) patients. Of these, $85 \%$ (95\% CI, 69.5-96.1) had a complete resolution of symptoms, $2.45 \%$ (95\% CI, 0.27-5.96) had a partial benefit, $0.19 \%$ (95\% CI 0.0-1.02) a persistent symptomatology, and $0.22 \%$ (95\% CI $0.0-0.95)$ a worsening of the clinical status.

Mean time of follow-up was reported in 21 out of 22 papers, and it was about 22.2 months.

Complications occurred in $7.75 \%$ (95\% CI 3.82-12.7) of patients. Out of 95 complications $66(6.3 \%)$ led to a transient deficit, while $16(0.15 \%)$ led to a permanent one. Among the severe complications, there were 3 cases of intracerebral or subarachnoid hemorrhage, 7 of new or persistent cranial nerve palsy, 6 of cerebral ischemia. Overall, mortality rate was 1 out of 1043 patients $(<0.001)$.

\section{Discussion}

This systematic review and meta-analysis including 22 studies on endovascular treatment of CS-dAVF showed that the most frequent clinical onset is characterized by ocular symptoms, essentially chemosis $(45.9 \%)$, proptosis $(41.5 \%)$ and oculomotor nerve palsy $(31.2 \%)$. A transvenous approach was preferred by the authors in almost $2 / 3$ of cases $(63.2 \%)$ and coils were used in more than half of patients. In general, the endovascular approach demonstrated a high percentage of radiological $(79.5 \%)$ and clinical $(85 \%)$ resolution of the fistula, and a low complication rate $(<8 \%)$, with an almost negligible incidence of permanent deficit.

\section{Clinical Presentation}

CS-dAVFs often present with various combinations of orbital signs and symptoms, which occur when the fistulous venous drainage involves the ophthalmic veins; however, venous congestion can seldom manifest with vague cognitive symptoms, such as concentration disorders [18].

Sometimes, CS-dAVFs may be associated with severe morbidity like threatening blindness, stroke and cerebral hemorrhage, especially if they are characterized by retrograde venous drainage within the cortical venous system [4, 27].

Our meta-analysis showed that the most frequently presentation symptoms were chemosis $(45.9 \%)$, proptosis $(41.5 \%)$ and ophthalmoplegia $(23.5 \%)$. Oculomotor palsy was reported in almost $1 / 3$ of patients $(31.2 \%)$ : among them, a VI cranial nerve palsy was objectivated in about 


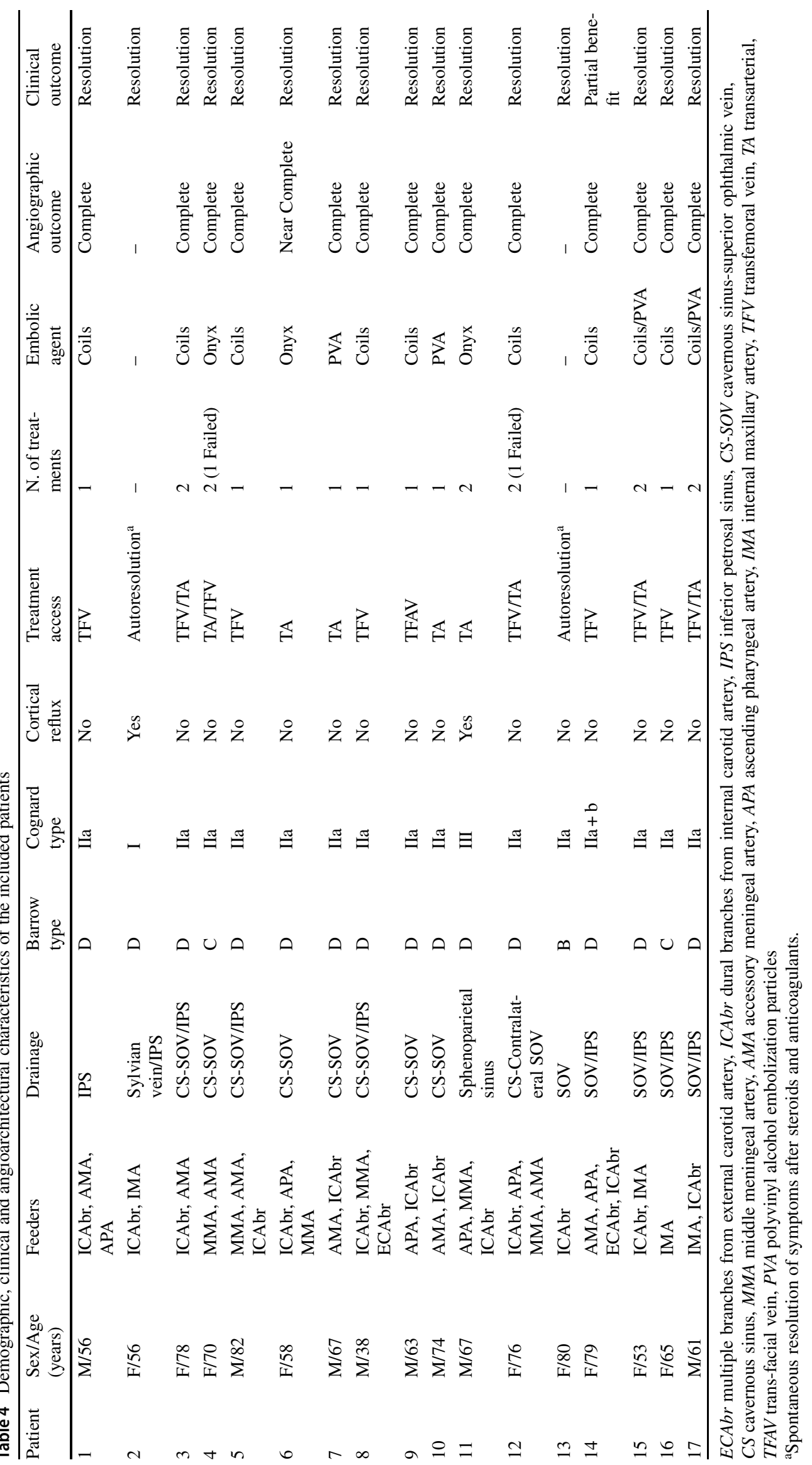


a

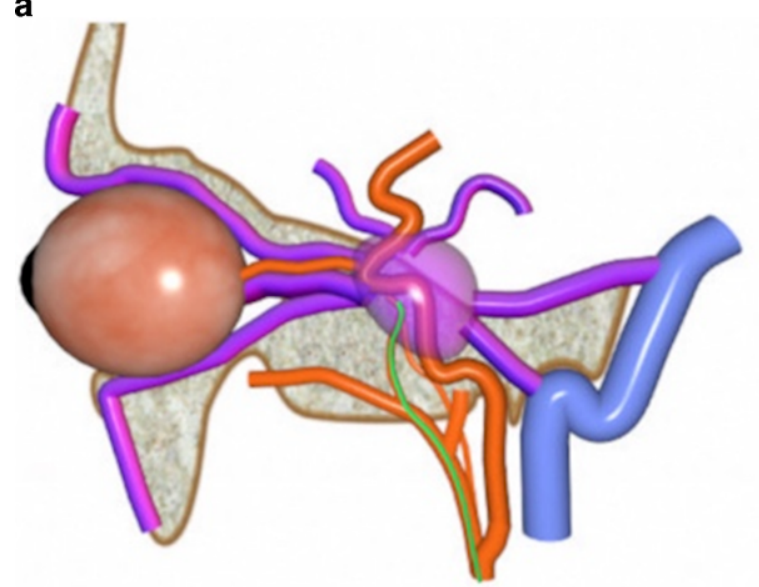

C

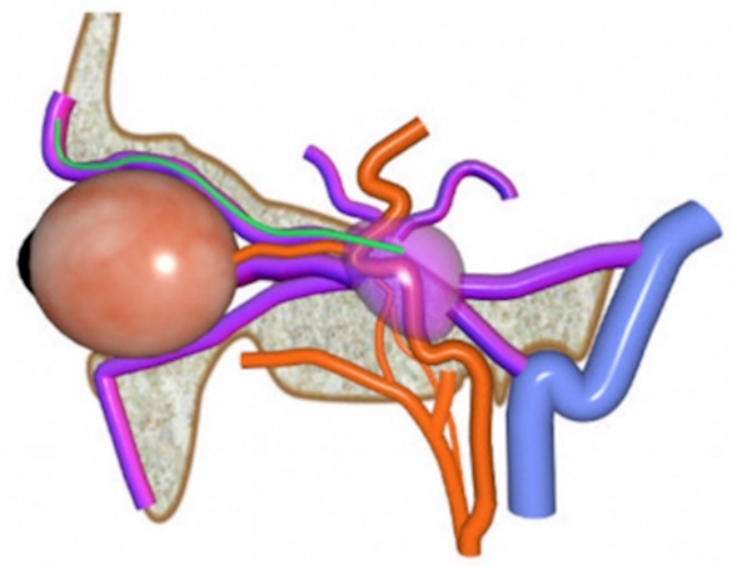

b

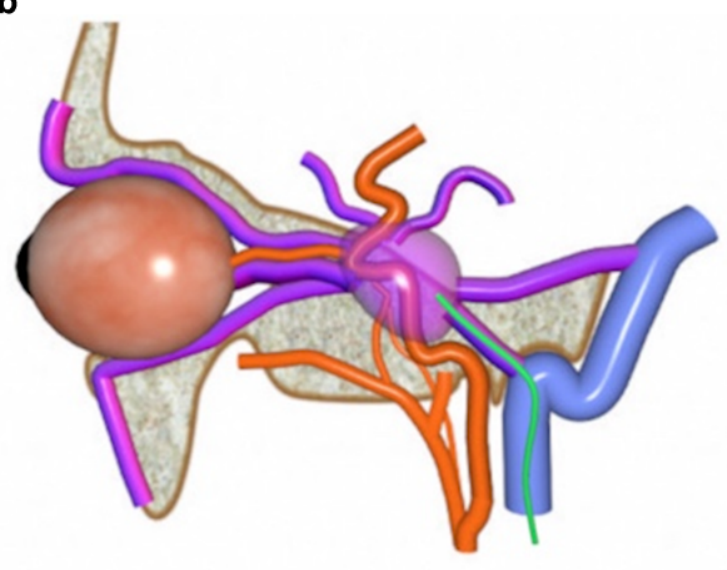

d

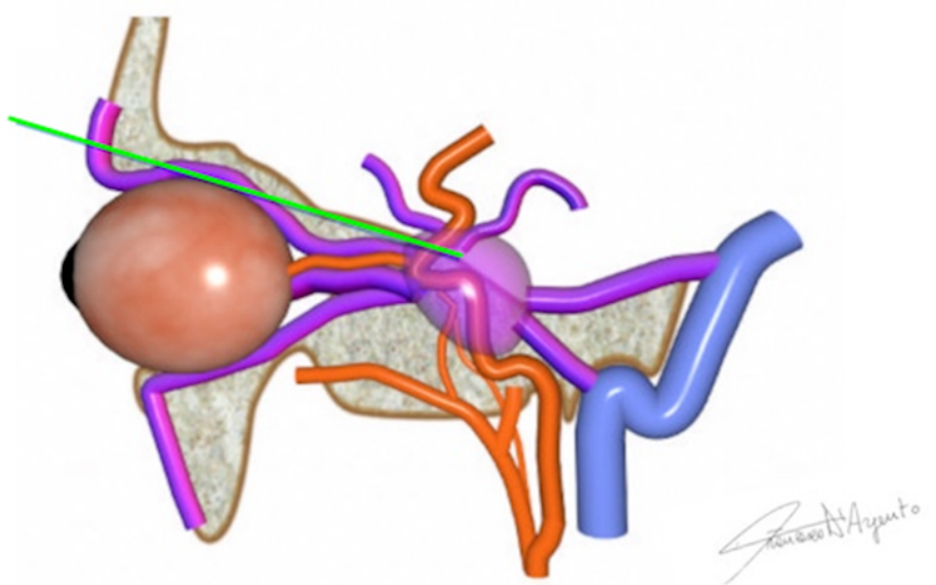

Fig. 2 Different approaches for endovascular treatment of CS-dAVF. a Arterial approach, b transvenous through inferior petrosal sinus approach, $\mathbf{c}$ transvenous through superior ophthalmic vein approach, $\mathbf{d}$ direct puncture of the cavernous sinus through the superior ophthalmic fissure

$4 / 5$, probably due to its inner course within the cavernous sinus, while a III and IV cranial nerves palsy overall in 1/5.

On the other hand, local pain, headache, pulsatile tinnitus and visual acuity reduction were less frequently reported; however, whether the first three may be relatively subjective symptoms, visual impairment and increase of the intraocular pressure reflect a condition of severe venous congestion observed in advanced cases [28, 29].

Anyway, clinical manifestations remain unpredictable in several cases without a precise explanation. Nowadays, the most accredited interpretation has been given by StiebelKalish et al., who suggested that the venous drainage pattern may be responsible for the different clinical onset in this type of fistulas [30].

\section{Endovascular Treatment}

The goal of CS-dAVFs treatment is to reduce cavernous sinus pressure by interrupting the fistulous communications and the retrograde flow towards the cortical venous system [6, 29, 31]. Before the advent of neurointerventional techniques, therapeutic options were limited [32], and in some cases a conservative management were preferred. Moreover, we found that the resolution of the fistula with a conservative treatment (e.g. manual carotid artery compression, steroid therapy) occurs as rarely as about $1.5 \%$ out of cases [33], but we cannot exclude that these were fistulas with a very low-flow with a spontaneous self-limiting behavior.

The preferred approach in literature is the transvenous embolization of the CS affected by the fistula [6], commonly acceding through the inferior petrosal sinus via the internal jugular vein ([4, 6]; Fig. 2).

Although some authors reported a certain success with transarterial approaches with liquid embolic agents, most of them preferred a transvenous approach releasing coils into the cavernous sinus. This approach, in fact, obviates the need for catheterization and embolization of the multiple tiny arterial feeders usually supplying the CS-dAVF [6, 31, 
$34,35]$, reducing the high risk of ischemic complications due to dangerous extracranial-intracranial anastomoses, or cranial nerve palsy due to vasa nervorum occlusion.

In agreement, we found that almost $2 / 3$ of the procedures were performed with transvenous access (63.2\%) compared with those performed with transarterial or combined approaches. Consequently, coils were the most frequently used embolizing agent (57.8\%), whereas other embolizing agents, such as glue, EVOH, PVA or various combinations of these, were used only in cases of transarterial or combined accesses.

Direct punctures of various head veins, such as the superior orbital vein, facial vein, sylvian vein, or directly the cavernous sinus through the superior orbital fissure have been proposed [36-40], but all these approaches are challenging and generally reserved for particular cases in which no other pathway to the fistula is accessible.

\section{Alternative Treatment Options}

Three main options are considered alternative to the interventional treatment for CS-dAVF. The first one is the conservative approach, which can be considered when symptoms are mild, no cortical venous drainage is present, and the angiographic assessment reveals a low-flow shunt. This includes medicinal management (prostaglandin analogues to control intraocular pressure, analgesics, steroids and anticoagulants to avoid occlusion of the superior ophthalmic vein), manual compression therapy and controlled hypotension. Occasionally a spontaneous occlusion may be observed without any medication [41].

The second is radiotherapy, which is suggested by some authors for selected cases where the endovascular treatment appeared unsuccessful, ineffective, contraindicated or considered too risky. Both irradiation with linear accelerator or gamma knife are reported, but this technique should be preferred in case of low-flow shunts and combined with transarterial embolization or manual compression as its efficacy in high-flow lesions remains questionable.

Finally, surgical occlusion can be proposed only to facilitate endovascular approaches, in selected cases [41].

\section{Complications}

According to the literature, complication rates appear variable, ranging from $2 \%$ to $20 \%[4,32,42]$, and some of them may result in significant morbidity.

In this meta-analysis, we found a pooled treatment-related complication rate of $7.75 \%$, which were for the majority transient; only a small number (16/1043) showed permanent deficits after treatment.

This appeared in accordance with previous studies reporting III, IV, V1, V2 or VI cranial nerves deficit as the most frequent transient complications [42]. Probably the occurrence of a new cranial nerve deficit or a worsening of a previous one after treatment often reflects an acute thrombosis of the cavernous sinus. Nevertheless, other authors suggested that CS coils overpacking represents the predominant cause of posttreatment cranial nerve palsy [43]. In any case, coil embolization has been associated with fewer complications than liquid embolic agents [5, 18].

Compared with transvenous embolization, transarterial approach has been associated with higher complication rate [18].

\section{Clinical and Radiological Follow-up}

Reported rates of complete CS-dAVFs occlusion after endovascular treatment range from $70 \%$ to $90 \%$. In the included studies, clinical and radiological follow-up were reported in different ways, sometimes in terms of time intervals, sometimes in terms of instrumental tests. The mean follow-up time ranged from 3 to 67 months (mean 22 months).

A follow-up angiographic evaluation was reported in about $4 / 5$ out of cases, documenting a pooled proportion of complete/near complete occlusion in more than $75 \%$ of patients.

In agreement, about $85 \%$ of patients showed a complete resolution of symptoms after treatment, with a negligible pooled percentage of patients showing symptoms persistence or worsening.

\section{Limitations}

Our study presents several limitations: clinical and radiological follow-up times were variable (3-67 months) thus, follow-up data may be biased by a high heterogeneity. All the included papers were observational, non-randomized, and non-comparative studies and data were often lacking in several details.

Finally, our results could be influenced by publication bias. In fact, we could miss some studies with worse outcomes that were performed and not published, distorting the evidence base; however, this study provides useful data to consider when dealing with endovascular treatment of CS-dAVFs.

\section{Conclusion}

A transvenous coiling is the most used endovascular treatment, achieving a high percentage of radiological and clinical resolution with a very low complication rate. In general, transvenous treatments showed less complications than 
transarterial approaches, and coil occlusion appeared safer than using liquid embolic agents.

Acknowledgements We thank Dr. Alexander Matthew D. for his support in retrieving data from his casuistry.

Author Contribution A.M.A., C.L.S. and A.P. conceived the presented idea. A.M.A., C.L.S., A.B. and A.R. performed the research in the literature. A.S., M.E.F., L.S. performed the statistical analysis. A.M.A., C.L.S., A.B., A.R. and F.D. wrote the manuscript. G.G., I.V., E.L. and A.P. reviewed the manuscript. A.P. supervised the finding and the study. All authors discussed the results and contributed to the final manuscript.

Funding Open access funding provided by Università Cattolica del Sacro Cuore within the CRUI-CARE Agreement.

Open Access This article is licensed under a Creative Commons Attribution 4.0 International License, which permits use, sharing, adaptation, distribution and reproduction in any medium or format, as long as you give appropriate credit to the original author(s) and the source, provide a link to the Creative Commons licence, and indicate if changes were made. The images or other third party material in this article are included in the article's Creative Commons licence, unless indicated otherwise in a credit line to the material. If material is not included in the article's Creative Commons licence and your intended use is not permitted by statutory regulation or exceeds the permitted use, you will need to obtain permission directly from the copyright holder. To view a copy of this licence, visit http://creativecommons.org/licenses/by/4. $0 /$.

\section{References}

1. Lasjaunias P, Chiu M, ter Brugge K, Tolia A, Hurth M, Bernstein M. Neurological manifestations of intracranial dural arteriovenous malformations. J Neurosurg. 1986;64:724-30.

2. Debrun GM, Viñuela F, Fox AJ, Davis KR, Ahn HS. Indications for treatment and classification of 132 carotid-cavernous fistulas. Neurosurgery. 1988;22:285-9.

3. Korkmazer B, Kocak B, Tureci E, Islak C, Kocer N, Kizilkilic O. Endovascular treatment of carotid cavernous sinus fistula: A systematic review. World J Radiol. 2013;5:143-55.

4. Meyers PM, Halbach VV, Dowd CF, Lempert TE, Malek AM, Phatouros CC, Lefler JE, Higashida RT. Dural carotid cavernous fistula: definitive endovascular management and long-term follow-up. Am J Ophthalmol. 2002;134:85-92.

5. Klisch J, Huppertz HJ, Spetzger U, Hetzel A, Seeger W, Schumacher M. Transvenous treatment of carotid cavernous and dural arteriovenous fistulae: results for 31 patients and review of the literature. Neurosurgery. 2003;53:836-56; discussion 856-7.

6. Gemmete JJ, Ansari SA, Gandhi DM. Endovascular techniques for treatment of carotid-cavernous fistula. J Neuroophthalmol. 2009;29:62-71.

7. Luo CB, Teng MM, Chang FC, Chang CY. Traumatic indirect carotid cavernous fistulas: angioarchitectures and results of transarterial embolization by liquid adhesives in 11 patients. Surg Neurol. 2009;71:216-22.

8. Lv X, Jiang C, Li Y, Yang X, Wu Z. Percutaneous Transvenous Embolization of Intracranial Dural Arteriovenous Fistulas with Detachable Coils and/or in Combination with Onyx. Interv Neuroradiol. 2008;14:415-27.

9. Miller NR. Diagnosis and management of dural carotid-cavernous sinus fistulas. Neurosurg Focus. 2007;23:E13.
10. Nishimuta Y, Awa R, Sugata S, Nagayama T, Makiuchi T, Tomosugi T, Hanaya R, Tokimura H, Hirano H, Moinuddin FM, Kamil M, Kibe A, Arita K. Long-term outcome after endovascular treatment of cavernous sinus dural arteriovenous fistula and a literature review. Acta Neurochir (Wien). 2017;159:2113-22.

11. Pashapour A, Mohammadian R, Salehpour F, Sharifipour E, Mansourizade R, Mahdavifard A, Salehi M, Mirzaii F, Sariaslani P, Ardalani GF, Altafi D. Long-Term Endovascular Treatment Outcome of 46 Patients with Cavernous Sinus Dural Arteriovenous Fistulas Presenting with Ophthalmic Symptoms. A Non-Controlled Trial with Clinical and Angiographic Follow-up. Neuroradiol J. 2014;27:461-70.

12. Satow T, Murao K, Matsushige T, Fukuda K, Miyamoto S, Iihara K. Superselective shunt occlusion for the treatment of cavernous sinus dural arteriovenous fistulae. Neurosurgery. 2013;73(1 Suppl Operative):ons 100-5.

13. Yoshida K, Melake M, Oishi H, Yamamoto M, Arai H. Transvenous embolization of dural carotid cavernous fistulas: a series of 44 consecutive patients. AJNR Am J Neuroradiol. 2010;31:651-5.

14. Zhang J, Lv X, Jiang C, Li Y, Yang X, Wu Z. Transarterial and transvenous embolization for cavernous sinus dural arteriovenous fistulae. Interv Neuroradiol. 2010;16:269-77.

15. Lee SH, Cho WS, Kang HS, Kim JE, Cho YD, Yoo DH, Han MH. Newly occurring cranial nerve palsy after endovascular treatment of cavernous sinus dural arteriovenous fistulas. J Neurointerv Surg. 2019;11:1168-72.

16. Rhim JK, Cho YD, Park JJ, Jeon JP, Kang HS, Kim JE, Cho WS, Han MH. Endovascular Treatment of Cavernous Sinus Dural Arteriovenous Fistula With Ipsilateral Inferior Petrosal Sinus Occlusion: A Single-Center Experience. Neurosurgery. 2015;77:192-9; discussion 199.

17. Yu SC, Cheng HK, Wong GK, Chan CM, Cheung JY, Poon WS Transvenous embolization of dural carotid-cavernous fistulae with transfacial catheterization through the superior ophthalmic vein. Neurosurgery. 2007;60:1032-7; discussion 1037-8.

18. Alexander MD, Halbach VV, Hallam DK, Cooke DL, Ghodke BV, Dowd CF, Amans MR, Hetts SW, Higashida RT, Meyers PM. Long-Term Outcomes of Endovascular Treatment of Indirect Carotid Cavernous Fistulae: Superior Efficacy, Safety, and Durability of Transvenous Coiling Over Other Techniques. Neurosurgery. 2019;85:E94-100.

19. Ertl L, Brückmann H, Patzig M, Dorn F, Fesl G. Patient reported long-term outcome after endovascular therapy of indirect dural carotid cavernous fistulas. PLoS One. 2020;15:e0231261.

20. Cha KC, Yeon JY, Kim GH, Jeon P, Kim JS, Hong SC. Clinical and angiographic results of patients with dural arteriovenous fistula. J Clin Neurosci. 2013;20:536-42.

21. Cheng KM, Chan CM, Cheung YL. Transvenous embolisation of dural carotid-cavernous fistulas by multiple venous routes: a series of 27 cases. Acta Neurochir (Wien). 2003;145:17-29.

22. de Castro-Afonso LH, Trivelato FP, Rezende MT, Ulhôa AC, Nakiri GS, Monsignore LM, Colli BO, Velasco-E-Cruz AA, Abud DG. Transvenous embolization of dural carotid cavernous fistulas: the role of liquid embolic agents in association with coils on patient outcomes. J Neurointerv Surg. 2018;10:461-2.

23. Jiang C, Lv X, Li Y, Wu Z. Transvenous treatment of cavernous dural arteriovenous fistulae with onyx and coils. Neuroradiol J. 2008;21:415-22.

24. Jia ZY, Song YS, Sheen JJ, Kim JG, Lee DH, Suh DC. Cannulation of Occluded Inferior Petrosal Sinuses for the Transvenous Embolization of Cavernous Sinus Dural Arteriovenous Fistulas: Usefulness of a Frontier-Wire Probing Technique. AJNR Am J Neuroradiol. 2018;39:2301-6.

25. Holland LJ, Mitchell Ranzcr K, Harrison JD, Brauchli D, Wong Y, Sullivan TJ. Endovascular treatment of carotid-cavernous sinus fistulas: ophthalmic and visual outcomes. Orbit. 2019;38:290-9. 
26. Griauzde J, Gemmete JJ, Pandey AS, Chaudhary N. Dural carotid cavernous fistulas: endovascular treatment and assessment of the correlation between clinical symptoms and the Cognard classification system. J Neurointerv Surg. 2017;9:583-6.

27. Halbach VV, Hieshima GB, Higashida RT, Reicher M. Carotid cavernous fistulae: indications for urgent treatment. AJR Am J Roentgenol. 1987;149:587-93.

28. Alam MS, Jain M, Mukherjee B, Sharma T, Halbe S, Jaisankar D, Raman R. Visual impairment in high flow and low flow carotid cavernous fistula. Sci Rep. 2019;9:12872.

29. Ringer AJ, Salud L, Tomsick TA. Carotid cavernous fistulas: anatomy, classification, and treatment. Neurosurg Clin N Am. 2005;16:279-95, viii.

30. Stiebel-Kalish H, Setton A, Nimii Y, Kalish Y, Hartman J, Huna Bar-On R, Berenstein A, Kupersmith MJ. Cavernous sinus dural arteriovenous malformations: patterns of venous drainage are related to clinical signs and symptoms. Ophthalmology. 2002;109:1685-91.

31. Tjoumakaris SI, Jabbour PM, Rosenwasser RH. Neuroendovascular management of carotid cavernous fistulae. Neurosurg Clin $\mathrm{N}$ Am. 2009;20:447-52.

32. Halbach VV, Higashida RT, Hieshima GB, Reicher M, Norman D, Newton TH. Dural fistulas involving the cavernous sinus: results of treatment in 30 patients. Radiology. 1987;163:437-42.

33. Higashida RT, Hieshima GB, Halbach VV, Bentson JR, Goto K. Closure of carotid cavernous sinus fistulae by external compression of the carotid artery and jugular vein. Acta Radiol Suppl. 1986;369:580-3.

34. Nelson PK, Russell SM, Woo HH, Alastra AJ, Vidovich DV. Use of a wedged microcatheter for curative transarterial embolization of complex intracranial dural arteriovenous fistulas: indications, endovascular technique, and outcome in 21 patients. J Neurosurg. 2003;98:498-506.

35. Cognard C, Januel AC, Silva NA Jr, Tall P. Endovascular treatment of intracranial dural arteriovenous fistulas with cortical venous drainage: new management using Onyx. AJNR Am J Neuroradiol. 2008;29:235-41.

36. Alexandre AM, Visconti E, Lozupone E, D'Argento F, Pedicelli A. Embolization of Dural Arteriovenous Fistula of the Cavernous Si- nus Through Percutaneous Ultrasound-Guided Puncture of the Facial Vein. World Neurosurg. 2017;99:812.e13-20.

37. Teng MM, Lirng JF, Chang T, Chen SS, Guo WY, Cheng CC, Shen WC, Lee LS. Embolization of carotid cavernous fistula by means of direct puncture through the superior orbital fissure. Radiology. 1995; 194:705-11.

38. Workman MJ, Dion JE, Tong FC, Cloft HJ. Treatment of Trapped CCF by Direct Puncture of the Cavernous Sinus by Infraocular Trans-SOF Approach. Case Report and Anatomical Basis. Interv Neuroradiol. 2002;8:299-304.

39. Fioravanti A, Fiaschi P, Badaloni F, Calbucci F. Transcranial approach for surgical-combined-endovascular treatment of a cavernous dural arteriovenous fistula: the superficial sylvian vein route. J Neurosurg Sci. 2020;64:405-7.

40. Trivelato FP, Manzato LB, Filho PMM, Ulhôa AC, Vanzin JR, Abud DG, Rezende MTS. Transorbital Cavernous Sinus Direct Puncture: Alternative to treat dural arteriovenous fistula. Clin Neuroradiol. 2018;28:55-61.

41. Benndorf G. Dural cavernous sinus fistulas. Diagnosis and endovascular therapy. Berlin, Heidelberg: Springer; 2010.

42. Kim DJ, Kim DI, Suh SH, Kim J, Lee SK, Kim EY, Chung TS. Results of transvenous embolization of cavernous dural arteriovenous fistula: a single-center experience with emphasis on complications and management. AJNR Am J Neuroradiol. 2006;27:2078-82.

43. Nishino K, Ito Y, Hasegawa H, Kikuchi B, Shimbo J, Kitazawa K, Fujii Y. Cranial nerve palsy following transvenous embolization for a cavernous sinus dural arteriovenous fistula: association with the volume and location of detachable coils. J Neurosurg. 2008;109:208-14.

44. Barrow DL, Spector RH, Braun IF, Landman JA, Tindall SC, Tindall GT. Classification and treatment of spontaneous carotid-cavernous sinus fistulas. J Neurosurg. 1985;62:248-56.

45. Cognard C, Gobin YP, Pierot L, Bailly AL, Houdart E, Casasco A, Chiras J, Merland JJ. Cerebral dural arteriovenous fistulas: clinical and angiographic correlation with a revised classification of venous drainage. Radiology. 1995;194:671-80. 